\title{
The attitudes and activities of pastors and faith leaders in Zimbabwe on the use of family planning methods among their members
}

Moses Alikalia

${ }^{\text {a }}$ Monitoring and Evaluation Officer, UMC-Health, Zimbabwe

\section{Abstract}

Background: Faith leaders are important gatekeepers in disseminating reproductive health messages and influencing positive behaviour change within communities. Faith leaders are seen as the most powerful, visible, and reachable form of authority, even trusted more than governments or non-profit organizations. In addition to providing counsel and advice aimed at enhancing health and wellbeing of the worshippers, faith leaders also play an important role in advocating and influencing what is taught in schools and what services are provided in healthcare facilities. Because of this influence, faith leaders often have an unparalleled opportunity-indeed, a moral obligation - to prioritize conversations about family planning, advocating, and closing the contraception gap.

The overall objective of this study was to ascertain the attitude and activities of pastors and faith leaders in Zimbabwe on the use of family planning methods among their members. The result revealed that some faith leaders believed that spreading information about family planning education was the responsibility of the government and tended to avoid such responsibility. However, through training on family planning advocacy, much can be achieved.

Methods: Qualitative study methods were used to better understand the attitude and activities of pastors and faith leaders in Zimbabwe on the use of family planning methods among their members. The participants of this survey were drawn from 8 of 10 provinces in Zimbabwe, which include: Bulawayo, Harare, Manicaland, Mashonaland Central, Mashonaland East, Mashonaland West, Masvingo, and Matabeleland North.

Paper-based questionnaires were answered by 24 pastors and 26 faith leaders in Zimbabwe (Table 1) through personal face-to-face meetings, while interviews were conducted with a select few pastors and faith leaders. The samples were drawn from randomly selected churches in Zimbabwe. Data was analysed using Epi info 7 and Microsoft Excel.

Results: Generally, the pastors and faith leaders understood the benefits of longer birth intervals for the health of their members and their children, and the need for them to be involved in family planning awareness. However, both seemed slow to incorporate family planning into their programs. The faith leaders indicated an interest in being a part of various forms of campaigns to promote family planning if they could be equipped with correct information on family planning. Many strongly believed family planning to be of great importance to them and their families in situations where their financial incomes were low, and that family planning could reduce the rate of abortion. A majority agreed family planning was in agreement with their religious beliefs. Some felt their members had basic information on family planning methods, but only 44 percent of the faith leaders actually counselled their members on family planning methods from time to time. Although many would like to be part of those who create awareness in their various places of 
worship, only 28 percent of them had the right information on family planning through training.

Conclusion: One major factor for the limited involvement of faith leaders in family planning awareness is their lack of correct information on family planning. The gap can be narrowed by organizing family planning advocacy training workshops. Networks such as Africa Christian Health Association Platform (ACHAP), the Islamic Medical Association of Zimbabwe (IMAZ), Zimbabwe Association of Church-Related Hospitals (ZACH), and Zimbabwe Council of Churches (ZCC) can also be leveraged to disseminate and accelerate the spread of family planning information.

\section{Introduction}

Zimbabwe was making progress in addressing the family planning needs of the people but progress has stagnated in recent years. According to the 2010-2011 Demographic Health Survey, 59 percent of currently married women use a contraceptive method, virtually unchanged from 60 percent in 2005-2006. Also since 2005-2006, the contraceptive prevalence rate (CPR) in urban areas has dropped from 70 percent to 62 percent. $^{1}$

According to the United Nations Population Fund (UNFPA), contraceptives prevent unintended pregnancies, reduce the number of abortions, and lower the incidence of death and disability related to complications of pregnancy and childbirth. If all women with an unmet need for contraceptives were able to use modern methods, an additional 24 million abortions (14 million of which would be unsafe), 6 million miscarriages, 70,000 maternal deaths, and 500,000 infant deaths would be prevented. ${ }^{2}$

Birth spacing is a key health intervention for reducing both maternal and infant mortality. When a woman spaces her pregnancies at least three years apart, she is more likely to have a healthy delivery, and her children are more likely to survive infancy. If a woman becomes pregnant too soon after giving birth, her body does not have time to recover and her risk for complications increases. To be able to space her pregnancies in the healthiest possible manner, a woman must have information on family planning methods.

Inadequate services, lack of knowledge of family planning, cultural barriers, religious barriers, and negative provider attitudes all prevent people from obtaining family planning services. Zimbabwe's CPR is one of the highest in sub-Saharan Africa. However, economic challenges in the last decade have led to a downward trend in some health indicators, including family planning use. Following the decline of both the economy and the health system in 2008, the government of Zimbabwe has relied on donor assistance to provide financial and human resources, including substantial support for commodities and service delivery. Donor funds for population assistance, which includes funding for family planning, maternal health programmes, system-related costs, HIV-AIDS, and basic research/ data/policy analysis, have more than quintupled from US\$50.8 million in 2008 to US\$275.7 million in 2012 (UNFPA 2014b). ${ }^{3}$

However, the level of knowledge, availability, and access to family planning services in reality is yet to justify the resources pushed into family planning projects. In addition to benefitting the health and well-being of people, increased investment in family planning contributes to broader development goals such as improvements in the overall status of women and reductions in poverty among families. Quality family planning services provide enormous health and economic benefits to families, communities, and countries. According to the UN Development Programme, for every $\$ 1$ spent on family planning, governments can save up to $\$ 6$ for other development priorities. 
According to the latest Zimbabwe national survey, 16 percent of young married women in that country reported having an unmet need for family planning, and 32 percent of sexually active unmarried women reported having an unmet need.

- The proportion of women with unmet need translates into more than 103,000 women - an estimated 93,000 married and 10,400 unmarried women.

- One outcome of high unmet need is unplanned pregnancies. In Zimbabwe, 31 percent of pregnancies among married women between the ages of 15 and 24 are unplanned. ${ }^{4}$

Recognizing the right to high-quality reproductive healthcare, and the link between population growths, gaps in family planning, and health and economic development, the Government of Zimbabwe made the following commitments (known as the FP2020 goals) at the 2012 London Summit on Family Planning.

- Increase the CPR to 68 percent by 2020 ;

- Reduce unmet need for family planning from 13 percent to 6.5 percent by 2020 ; and

- Increase access to a comprehensive range of family planning methods, including long-acting and permanent methods (LAPMs). ${ }^{1}$

However, in most of these plans, the role of faith leaders is mostly ignored.

The government, civil society organizations, and other policymakers must recognise that faith leaders and individual congregations are important gatekeepers in disseminating reproductive health messages and influencing positive behavioural change within communities. There has been a lot of improvement in the efforts of faith-based organizations (FBOs) in creating awareness and educating women and men on family planning methods, particularly in Zimbabwe. FBOs are also one of the key messengers in reaching out to conservative religious and cultural communities.

Some FBOs consider family planning to be central to their mission in supporting women, children, and

68 | Christian Journal for Global Health 4(2) families, and integral to their efforts in promoting global health based on evidence that birth spacing is critical to lowering the number of deaths and disabilities. As trusted messengers with deep roots in communities, FBOs can and do play importantsometimes essential - roles in providing contraceptive services, raising awareness, and advocating for family planning. The United Methodist Church has been one of the strongest FBOs supporting family planning globally, both theologically and in practice. $^{5}$

FBOs are one of the key healthcare providers in Zimbabwe. For instance, the Zimbabwe Association of Church-Related Hospitals (ZACHs), which has more than 60 member hospitals and 66 smaller healthcare institutions, has been providing family planning services in Zimbabwe since 1982, including a range of contraceptive methods (such as injection, pill, implant and barrier methods). In 2009 alone, ZACHs had more than 40,000 first visits for family planning, more than 100,000 repeat visits, and more than 4,000 referrals. ${ }^{6}$ Some of the factors possibly slowing down the efforts to expand knowledge and access to family planning in Zimbabwe are the prevailing social/cultural attitudes and religious beliefs of community members.

Contraception is against the teachings of 28 percent of faith leaders in our study, and this prevents them from supporting positive actions around family planning. This makes it critical to win the support of faith leaders as they are likely to influence the perception of their followers. The direct and indirect benefits, however, of women planning their families are priceless and countless: smaller family sizes, better health for both children and mothers, less economic burden on the families, and women's continued economic contribution to the greater community. By meeting all the unmet need for family planning, maternal mortality rates would drop by a third, and the need for abortion would be reduced significantly. ${ }^{7}$

Faith leaders need to be sensitized on family planning to be able to embrace these community responsibilities, educate themselves about the various contraceptive options for couples, and engage their local 
governments and healthcare providers on the topic. Local action is one of the major tools that can allow us to meet the family planning needs of millions and build a better world for future generations. The following organizations were engaged in planning and executing this study: The United Methodist Church Episcopal Areas Zimbabwe Health Board, The United Methodist Church Zimbabwe Episcopal Areas, and Zimbabwe Council of Churches. the UMC Health Board Coordinator (Mrs. Hannah Mafunda) and Prof. Ezra Chitando. The data collection process took place smoothly with the support of the Zimbabwe Council of Churches and other volunteers. To be eligible to participate in the study, the participant had to be a pastor or faith leader and agree to participate. Data was analysed using Epi info 7 and Microsoft Excel.

\section{Methods}

The study employed a qualitative study method to better understand the attitudes and activities of pastors and faith leaders in Zimbabwe on the use of family planning methods among their members. The participants of this survey were drawn from 8 provinces of 10 in Zimbabwe, which include Bulawayo, Harare, Manicaland, Mashonaland Central, Mashonaland East, Mashonaland West, Masvingo, and Matabeleland North.

Paper-based questionnaires were answered by 24 pastors and 26 faith leaders in Zimbabwe through personal face-to-face meetings while interviews were conducted with a select few pastors and faith leaders (Table 1). Some of these faith leaders established mission hospitals and clinics. The samples were drawn from randomly selected churches in Zimbabwe.

The questionnaire was designed with support from
Table 1: Respondents' information

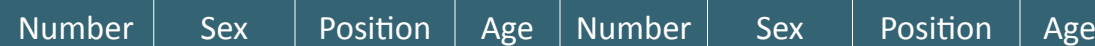

\begin{tabular}{|l|l|l|l|l|l|l|l|}
\hline 1 & Male & Pastor & 40 & 26 & Female & Leader & 23 \\
\hline 2 & Male & Pastor & 30 & 27 & Male & Pastor & 22 \\
\hline 3 & Male & Leader & 42 & 28 & Female & Leader & 24 \\
\hline 4 & Female & Leader & 25 & 29 & Male & Leader & 40 \\
\hline 5 & Male & Pastor & 34 & 30 & Female & Pastor & 24 \\
\hline 6 & Male & Pastor & 36 & 31 & Male & Pastor & 24 \\
\hline 8 & Male & Leader & 40 & 32 & Female & Leader & 22 \\
\hline 9 & Male & Pastor & 43 & 33 & Male & Leader & 24 \\
\hline 10 & Female & Leader & 38 & 34 & Male & Pastor & 35 \\
\hline 11 & Female & Leader & 38 & 35 & Female & Leader & 60 \\
\hline 12 & Female & Pastor & 30 & 36 & Male & Leader & 47 \\
\hline 13 & Male & Pastor & 41 & 37 & Male & Leader & 45 \\
\hline 14 & Male & Pastor & 50 & 38 & Male & Pastor & 47 \\
\hline 15 & Male & Pastor & 50 & 40 & Female & Leader & 41 \\
\hline 16 & Male & Leader & 24 & 41 & Female & Leader & 49 \\
\hline 17 & Female & Leader & 48 & 42 & Male & Pastor & 37 \\
\hline 18 & Male & Leader & 28 & 43 & Female & Leader & 36 \\
\hline 19 & Male & Pastor & 52 & 44 & Male & Pastor & 33 \\
\hline 20 & Female & Leader & 33 & 45 & Male & Pastor & 40 \\
\hline 21 & Male & Pastor & 44 & 46 & Male & Pastor & 27 \\
\hline 22 & Female & Leader & 31 & 47 & Male & Pastor & 41 \\
\hline 23 & Male & Leader & 50 & 48 & Female & Pastor & 30 \\
\hline 24 & Male & Leader & 41 & 49 & Male & Pastor & 35 \\
\hline 25 & Female & Leader & 37 & 50 & Male & Pastor & 33 \\
\hline & & & & & & 44 \\
\hline
\end{tabular}

July 2017 | 69 


\section{Results}

Generally, the pastors and faith leaders understood the advantages of longer birth intervals, the health benefits for their members and their children, and the need for them to be involved in family planning awareness. However, both groups seemed slow to incorporate family planning into their programs. The results of this study revealed that some faith leaders believed that spreading information about family planning education was the responsibility of the government, and they tended to avoid such responsibilities. However, they indicated an interest in being a part of various forms of campaigns to promote family planning if they could be well equipped with correct information on family planning. The gap between family planning knowledge and faith leaders could be narrowed by organizing family planning advocacy training for religious leaders in Zimbabwe on how to effectively construct and deliver family planning messages. Networks such as Africa Christian Health Associations Platform (ACHAP), ZACH, and Zimbabwe Council of Churches (ZCC) can also be leveraged to disseminate and accelerate the spread of family planning messages.

\section{Family planning and its benefits}

Ninety-six percent of the respondents strongly believe family planning is of great importance to them and their families, and 92 percent agree that the number of children one has should correlate with their financial income. (Figure 1).

They understand the benefits of longer birth intervals for the health benefits of their members and their children. When women and couples are empowered to plan whether and when to have children, women are better enabled to complete their education and their earning power is improved. This strengthens their economic security, their well-being and that of their families.

It was observed that women that are on family planning have a better nutritional status with a higher average weight and body mass index. Their children weigh more and were more likely to be immunized for diphtheria, pertussis, and tetanus (DPT); polio; and measles. Families using family planning methods are more likely to have higher incomes, greater savings and assets, higher educational achievements, and improved access to water.

\section{Family planning and abortion/religious beliefs}

Eighty-two percent of the respondents agree that family planning can reduce the rate of abortion, while some think family planning encourages abortion. Seventy-two percent agree family planning is in agreement with their religious beliefs, while 28 percent say family planning is not in agreement with their religious beliefs. This explains the role of others influencing their views on family planning (Figure 2).

\section{Figure 1}

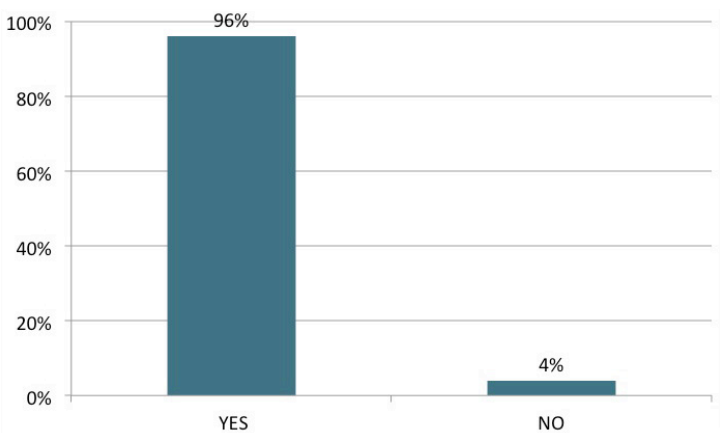

Do you think family planning is good?

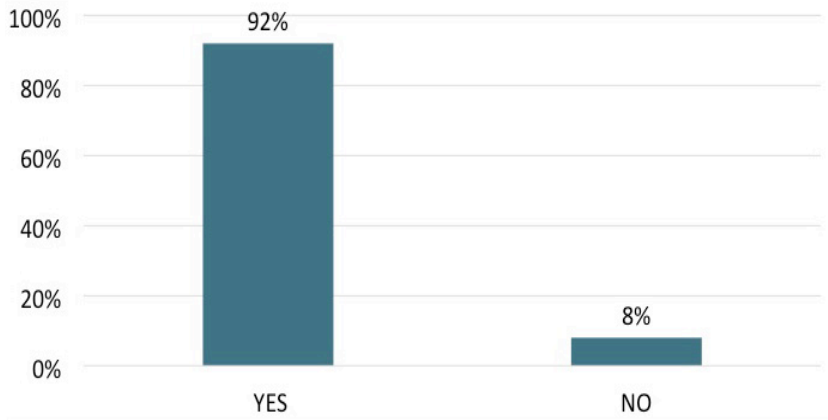

The number of children one has should correlate with financial income. 
Figure 2

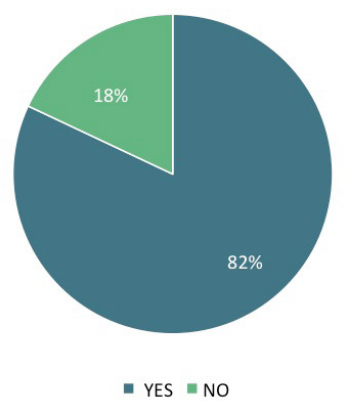

Does FP reduce the rate of abortion?

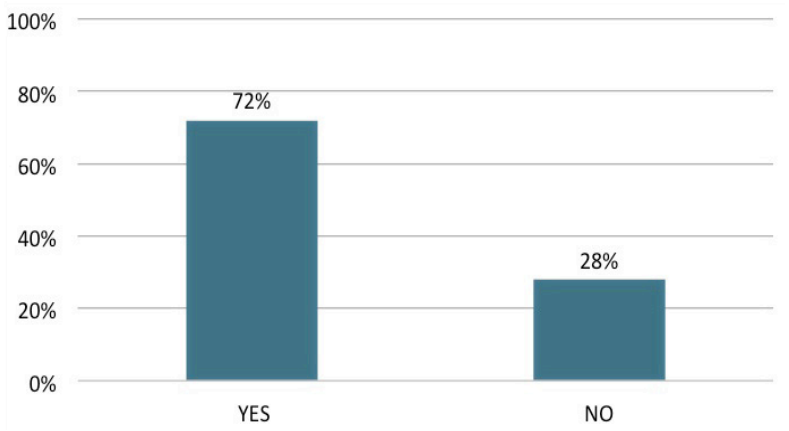

Is FP in agreement with your religious beliefs?

People tend to learn the myths of family planning from others in their communities. These people often get inaccurate information or are directly counselled by others not to engage or use family planning. As mentioned earlier, some of the factors possibly slowing down the efforts to expand knowledge and access to family planning in Zimbabwe are the prevailing socio-cultural attitudes and religious beliefs of community members. Contraception is against the teachings of 28 percent of religious leaders in this study, and this prevents them from supporting artificial methods. However, some of them support natural methods and would encourage those who want to practice them. This makes it critical to win the support of religious leaders as they are likely to influence the perception of their followers. In addition to the myths described above, many

\section{knowledge of family planning}

also mention real side effects as a barrier to use. The most common side effects expressed by the respondents are weight changes, bleeding, lack of sexual desire, headaches, and high blood pressure.

\section{Family planning counselling and people's}

It was discovered from the study that only 62 percent of the faith leaders felt their members have basic information on family planning methods and only 44 percent of the faith leaders actually counsel their members on family planning methods from time to time (Figure 3).

Religious leaders need to be sensitized on family planning in order to embrace these community responsibilities, educate themselves about the various contraceptive options for couples, and engage their local governments and healthcare providers on the topic. Local action is one of the major tools required to meet the family planning needs of millions and build a better world for future generations.

Figure 3

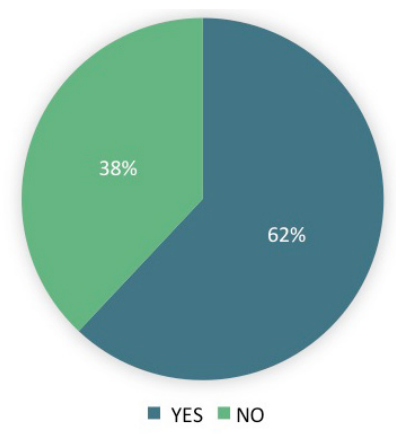

Do your members have info on FP?

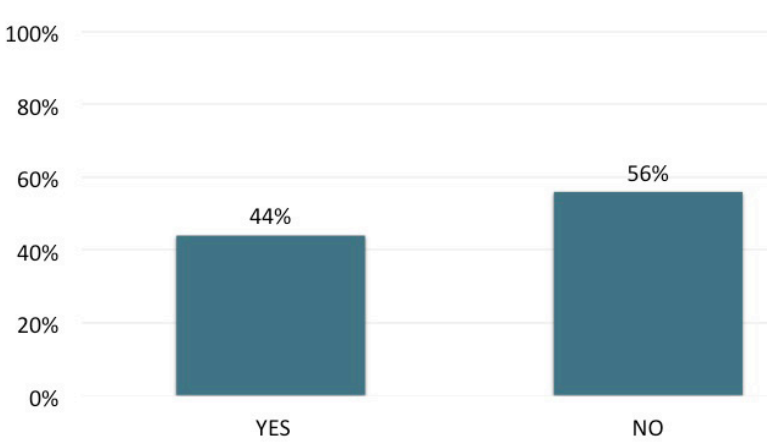

Do you counsel your members on FP? 


\section{Willingness to create awareness on family planning}

Seventy-six percent of the faith leaders understand the importance of family planning and would like to be part of those who create awareness in their places of worship, but are handicapped as only 28 percent of them have the right information on family planning through training (Figure 4).

Lack of knowledge is one of the major barriers to the use of family planning, with many women not understanding when they are able to fall pregnant, not knowing what family planning methods are available, or having incorrect perceptions about the health risks of modern methods. Religious leaders are important gatekeepers in disseminating family planning messages and influencing positive behavioural change within communities, and need to be well equipped with correct information on family planning to be able to deliver the message effectively to the people.

\section{Discussion}

These findings demonstrate that people's perceptions and knowledge of family planning determines whether or not they will use it. Those that have information on the benefits of family planning are likely to use contraceptive methods, as will those who perceive that family planning will help them to improve their standard of living. Furthermore, this analysis suggests that there is a strong relationship between attitudes toward family planning

Figure 4

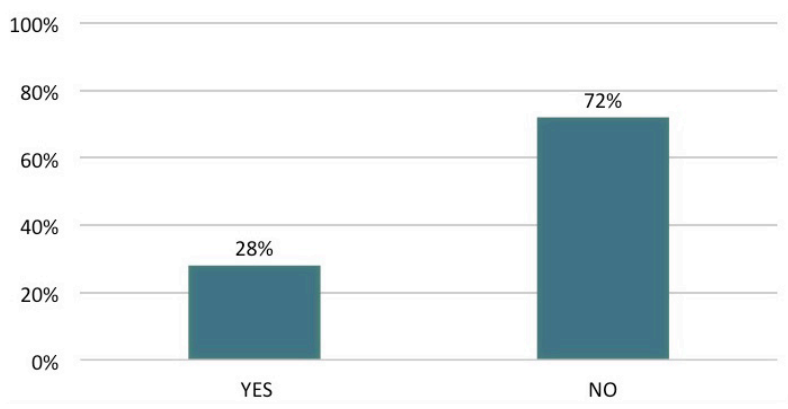

Have you attended any training on FP? and contraceptive use, faith leaders' knowledge of family planning methods, and counselling of their members.

The study also shows the impact social support can have on contraceptive use. Faith leaders who are important gatekeepers in disseminating family planning messages have influence and positive effects on their members' contraceptive behaviour. Therefore, it is important to identify those influential faith leaders who can act as social change agents and to increase their support for contraception. Their endorsement of family planning may thereby increase contraceptive use among their members and other community members. Finally, it is also very important to leverage the support of religious networks such as ACHAP, ZACH, IMAZ, and ZCC to disseminate and accelerate the spread of family planning messages.

\section{Recommendations}

In order to gain the full benefit from the engagement of pastors and faith leaders in the efforts to promote family planning in Zimbabwe, government, civil society organizations, and other policymakers will need to consider equipping and engaging faith leaders in their efforts. Below are some of the practical interventions to engaging faith leaders on the issues of family planning:

Organize family planning advocacy training for selected influential faith leaders in Zimbabwe to equip them with correct information, communica-

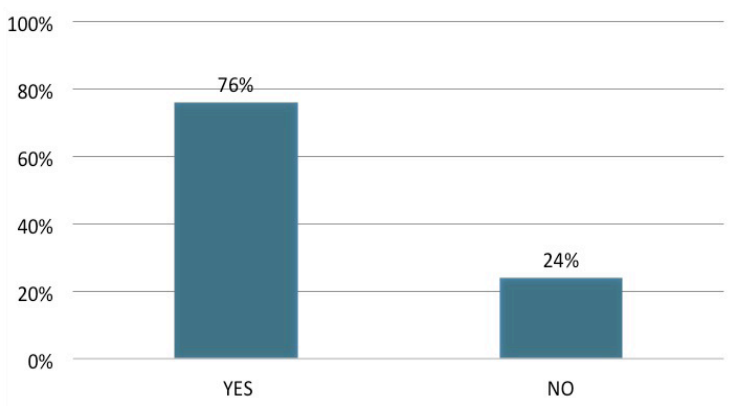

Do you like to be part of faith leaders who talk about FP in their place of worship? 
tion skills, appropriate language for family planning awareness, and training to overcome barriers to the use of family planning.

Develop family planning manuals for faith leaders to guide them on the appropriate language to use when communicating with their members. There are a number of challenges to improving access to family planning information and services. Efforts to increase access must be sensitive to cultural and national contexts, and must consider economic, language, geographic, and age disparities within countries.

Organize communication programs for various media outlets to involve trained faith leaders in optimizing their voices beyond the pulpit. The media communication program could be on radio, television, social media, and other forms of communication, including those in local languages, particularly to reach out to those in rural areas. Various myths and barriers will be addressed on these platforms. Hopefully, these positive messages will lead to a change of attitude toward family planning and even compel policymakers to act positively.

Networks such as ACHAP, ZACH, IMAZ, and ZCC can be leveraged to disseminate and accelerate the spread of family planning messages. FBOs are one of the key healthcare providers in Zimbabwe. For instance, ZACH has more than 60 member hospitals and 66 smaller healthcare institutions that have been providing family planning services in Zimbabwe since 1982, including a range of contraceptive methods (such as injection, pill, implant, and barrier methods) ${ }^{8}$

\section{Conclusion}

Faith leaders are trusted and respected in Zimbabwe. Women, men, and youths rely on them for guidance on many personal and family matters, including life-cycle, reproductive health, and family planning decision-making. They share opinions about the acceptability and advisability of family planning, birth spacing, and other reproductive health topics, and help their followers make important life decisions through individual and premarital counselling, and through weekly sermons. Essentially, religious leaders play an active role in the dissemination of accurate information about family planning.

Access to family planning information is also central to achieving gender equality. When women and couples are empowered to plan whether and when to have children, women are better enabled to complete their education, women's autonomy within their households is increased, and their earning power is improved. This strengthens their own and their family's economic security and well-being. Cumulatively, these benefits contribute to poverty reduction and development. Lack of knowledge is one of the major barriers to the use of family planning methods, with many people not understanding the importance of family planning, not knowing what family planning methods are available, or having incorrect perceptions about the health risks of modern methods. Faith leaders are important gatekeepers in disseminating family planning messages and influencing positive behavioural change within communities. This makes it critical to win the support of faith leaders as they are likely to influence the perception of their followers, empowering and equipping them with relevant skills to effectively disseminate family planning messages. 


\section{References}

1 Resource requirements for family planning in Zimbabwe. Health Policy Project, USAID. June 2014. Available from: https://www.healthpolicyproject.com/pubs/332 ResourceRequirmentsforFPinZimbabweFinal.pdf

2 Adding it up: the costs and benefits of investing in sexual and reproductive health. United Nation Population Fund. 2014. Available from: http://www.unfpa.org/adding-it-up

3 Evaluation of the UNFPA support to family planning services. UNFPA. 2008-2013. Available from: http://www. unfpa.org/sites/default/files/admin-resource/Final Family Planning_Country_Note_ZIMBABWE_0.pdf

4 Youth reproductive health: satisfying unmet need for family planning. Population Reference Bureau. September 2015. Available from: http://www.prb.org/pdf15/unmetneed-factsheet-zimbabwe.pdf

5 Barot S. A common cause: faith-based organizations and promoting access to family planning in the developing world. Guttmacher Policy Review. December 10, 2014.
Available from: https://www.guttmacher.org/gpr/2013/12/ common-cause-faith-based-organizations-and-promoting-access-family-planning-developing

6 Kaiso Rev Canon G, Ragab A R. Leap of faith: why religious leaders have a moral duty to promote family planning. The Citizen. January 17, 2016. Available from: http:// allafrica.com/stories/201601181555.html

7 Maternal health: the church's role. The Book of Resolutions of the United Methodist Church. The United Methodist Publishing House. 2012. Available from: http://www. umc.org/what-we-believe/maternal-health-the-churchs-role

8 Faith-based organizations as partners in family planning: working together to improve family well-being. Institute for Reproductive Health. Georgetown University. August 2011. Available from: http://irh.org/wp-content/ uploads/2013/04/IRH_Faith_Report.oct_5.reduced.pdf

Peer Reviewed

Competing Interests: None declared.

Acknowledgements: The author gratefully acknowledges the efforts of Zimbabwe Council of Churches and the following people: Prof. Ezra Chitando, Theology Consultant for the Ecumenical HIV and AIDS Initiatives and Advocacy (World Council of Churches)/ Department of Religious Studies, University of Zimbabwe; Mrs. Hannah Mafunda, Zimbabwe United Methodist Church Episcopal Area Health Board Coordinator; Rev. Dr. Kenneth Mtata, General Secretary Zimbabwe Council of Churches; Mr. Simon Mafunda, Zimbabwe East Annul Conference Lay leader; Miss Rutendo M. Chapwanya, Medical Laboratory Sciences student at University of Zimbabwe; Mr. Tapiwa Blessing Kanengoni, Global Mission Fellow (2016-2018) serving in Brazil.

Correspondence: Moses Alikali, mosesalikali@gmail.com

Cite this article as: Alikali M. The attitude and activities of pastors and faith leaders in Zimbabwe on the use of family planning method among their members. Christian Journal for Global Health. July 2017; 4(2):66-74; https://doi.org/10.15566/cjgh.v4i2.188.

(C) Alikali M. This is an open-access article distributed under the terms of the Creative Commons Attribution License, which permits unrestricted use, distribution, and reproduction in any medium, provided the original author and source are properly cited. To view a copy of the license, visit http://creativecommons.org/licenses/by/4.0/ 